\title{
Algumas possibilidades de interação entre Arte Urbana, Joseph Wright e o Ensino de Óptica
}

\author{
Milene Dutra da Silva \\ Mário Sérgio Teixeira de Freitas \\ Awdry Feisser Miquelin
}

\section{Resumo}

Nesta investigação, o ensino de alguns tópicos da óptica foi repensado relacionando ciência e arte, entendidas como expressões humanas inseparáveis e instrumentos de compreensão do mundo. Foi desenvolvida uma unidade didática envolvendo conceitos da óptica geométrica no ensino médio, norteada pela pedagogia dialógico-problematizadora de Paulo Freire, e aplicada em três colégios estaduais em Curitiba. O tema gerador foi a Arte Urbana, presente no universo dos nossos educandos. A discussão gerada abordou o conceito de Ciência e na problematização utilizou-se a tela "An Experiment on a Bird in the Air Pump" (1766), de Joseph Wright of Derby. A estratégia de pesquisa foi do tipo observação participante e o tratamento de dados pelo método comparativo constante. Os dados foram obtidos no estilo cooperativo e a categoria geral definida para análise foi a das "Perspectivas tidas pelos sujeitos", consoante com a concepção freiriana de educação centrada nos sujeitos envolvidos e suas vivências.

Palavras-chave: Ensino de Óptica, Joseph Wright, Arte e Ciência.

\begin{abstract}
Some possibilities of interaction between Street Art, Joseph Wright and the Optic's teaching

In this investigation, we rethink the learning on some topics of Optics, based on the relationship between Science and Art, as inseparable human expressions and world representations. A didactic unit was developed, aiming the transposition of optical concepts in high school. The intervention was based on the dialogical and problematically presented approach due to Paulo Freire, applied at three State colleges in Curitiba. The theme-generator was Street Art, presented as the learner's universe, generating a discussion concerning concept of Science and questioning used the painting "An Experiment on a Bird in the air pump", by Joseph Wright of Derby (1766). The research strategy was participant observation, processing data by constant comparative method, which were obtained from the cooperative style, and the general category set for analysis was that of "Perspectives taken by subject", which is consonant with the Freirian conception for education centered on the subjects involved and their experiences.
\end{abstract}

Keywords: teaching optics, Joseph Wright, art and science. 


\section{Sobre o ensino de física, a pesquisa e seus objetivos}

A disciplina escolar Física passa atualmente por um período de reformulações. Em fóruns adequados (incluindo entre estes as escolas) são discutidos os conteúdos que devem ser ensinados e suas metodologias, pois se reconhece que o ensino de Ciências quando desenvolvido a partir de modelos ultrapassados é inadequado ao grande e diversificado público estudantil presente hoje no ensino médio das escolas públicas de todo país. Os documentos oficiais (tais como os PCN e as DCE) apontam para o ensino de uma Ciência contextualizada, na qual a conceituação teórica e o tratamento matemático das questões sejam apresentados de forma que tenham significação para o estudante, possibilitando a alfabetização científica necessária para convivência no mundo contemporâneo. Com este direcionamento, algumas alternativas para o enriquecimento metodológico do ensino de Física têm sido discutidas, entre elas pode-se citar a inserção da História e Filosofia da Ciência, as questões de CTSA, a experimentação e as relações dos assuntos da Física com outras disciplinas e áreas do conhecimento de modo a favorecer uma formação científica, histórica e humana, que possibilite a reflexão e a participação crítica na sociedade onde vive (BRASIL,1999).

Neste contexto, foi desenvolvido um trabalho com o objetivo de investigar como as artes plásticas e alguns aspectos da história da ciência podem auxiliar pedagogicamente na apropriação dos conceitos relativos aos fenômenos da óptica geométrica. A unidade didática fruto deste estudo foi utilizada como objeto de pesquisa qualitativa em educação em seis turmas de ensino médio de três colégios estaduais situados em Curitiba-PR.

\section{Processo de ensino e aprendizagem - A perspectiva de Paulo Freire}

A metodologia da pesquisa se baseou na concepção educacional dialógico problematizadora freiriana. A teoria de Paulo Freire é amplamente conhecida da comunidade da educação, foi intensamente publicada e seus livros são gratuitamente ou facilmente disponíveis. No entanto, se pretende apresentar neste texto sinteticamente os conceitos de dialogicidade e de problematização cuja interpretação se faz fundamental para compreensão da proposta. Por dialogicidade "a essência da educação como prática da liberdade" (FREIRE, 1987, p. 16) entendese que o educador esteja aberto para investigar a realidade de seus educandos, que desta maneira inicie a busca do conteúdo programático neste diálogo. No processo de investigação, que Paulo Freire chamou de universo temático dos educandos, é que o educador encontra os temas geradores a partir dos quais é possível planejar aulas em que o conhecimento científico tenha significação, desperte interesse e acompanhe o educando quando este tenha deixado os bancos escolares para assim ser agente de transformação em sua realidade. Quanto ao conceito de problematização, ela acontece quando se atinge a superação da visão ingênua e acrítica do 
mundo; quando o educando é tensionado e provocado a resolver obstáculos que enfrenta lançando mão dos seus conhecimentos primeiros em comunhão com conhecimentos que adquiriu para interpretar ou resolver de forma mais abrangente e elaborada as suas demandas.

Nesta pesquisa as atividades aplicadas em sala foram organizadas em três momentos pedagógicos, que são proposição dos pesquisadores José André Angotti e Demétrio Delizoicov (2011) e consoantes com os conceitos de codificação, descodificação e recodificação em Freire.

\subsection{Das relações entre a Arte e a Física - Imaginação e Criatividade}

O referencial a partir da concepção educacional de Paulo Freire possibilita reflexão sobre a função da curiosidade no processo de ensino-aprendizagem. É sobre o caminho feito (com a utilização das atividades propostas) para passagem da chamada "curiosidade ingênua" para "curiosidade epistemológica" mais crítica, rigorosa e reflexiva que se trata quando se busca uma forma de ensinar que resgate no estudante a imaginação e a criatividade fundamentais para que o ato de aprender seja tão prazeroso (FREIRE, 2011, p. 31). É interessante, portanto, contextualizar esta abordagem no âmbito das relações entre Física e Arte.

Quando se fala em ciência, especialmente em Física, é trivial perceber que a compreensão desta exige do leitor conhecimento prévio da sua linguagem. O uso de símbolos, gráficos e operadores matemáticos faz parte desta "iniciação" exigida. Esta linguagem é uma das formas de representação das quais a ciência se utiliza para sistematizar suas leis e teorias. A função destas leis e teorias construídas pela ciência é a explicação dos fenômenos da natureza, do mundo que nos cerca e (de certa forma) fazer previsões sobre esta realidade. Ou seja: a ciência explica e representa; e para fazê-lo é necessário imaginar (o que ainda se busca conhecer) e usar da criatividade (por exemplo, para representar o que não se visualiza no mundo material) (PIETROCOLA, 2004, p. 122). Quando se fala em arte, inicialmente se tem a impressão de que esta faz parte de um "um mundo diferente" do da ciência e de que o artista tem total liberdade para expressar-se em uma obra. A verdade é que o artista (bem como o cientista) trabalha baseandose no seu conhecimento, na sua interpretação deste e produz em acordo com as "leis" da escola ou movimento no qual está inserido fazendo uso da tecnologia que lhe seja acessível. Tanto o cientista como o artista imaginam, criam e representam utilizando-se de diferentes métodos, porém atuam construindo e interferindo na realidade sócio histórica na qual estão culturalmente inseridos.

\subsection{Sobre Joseph Wright, a Ciência e a Arte no século XVIII}

A escolha por se utilizar na etapa de problematização, da imagem de um trabalho deste artista se deu pelos temas presentes em sua obra. Muitas de suas telas retratam cenas que 
remetem à prática da Ciência da sua época, e também porque se observa em suas obras que a representação de efeitos luminosos (sombras, reflexos, penumbra e transparência) e os recursos da perspectiva (como fidelidade ao ponto de fuga) estão presentes e são importantes recursos pedagógicos.

Joseph Wright nasceu em Derby, na Inglaterra no ano de 1734 (CUMMING, 1998, p. 68). Desenvolveu sua pintura desde jovem iniciando por retratos e evoluindo para temas científicos. Acredita-se que o interesse por temas que relacionam Arte, Filosofia e Ciência tenha sido fortalecido por suas relações de amizade com estudiosos e outros pesquisadores da época que também faziam parte do chamado Círculo Lunar (GORRI, 2009, p. 184). Ou seja, o contexto social em que Joseph Wright estava inserido foi determinante para a riqueza de conhecimentos que ele demonstra na sofisticação de seus temas e em sua técnica detalhista e apurada.

O século XVIII é o final da Idade Moderna (1453-1789), período fortemente marcado pela transição de valores e de grandes modificações na organização social e política da Europa. Dentre as principais pode-se citar a ascensão da burguesia, a diminuição do poder da igreja sobre a vida cotidiana da população e a primeira revolução industrial. A necessidade de aumentar a produção de bens de consumo foi motivada por questões de ordem sócio econômica que alavancaram também a demanda por conhecimentos científicos necessários para o desenvolvimento tecnológico daquele momento histórico. Exemplo disso são as Leis da Termodinâmica, área que se desenvolveu pela necessidade de aumentar a eficiência das primeiras máquinas a vapor (do século XVII). O movimento histórico que deu suporte filosófico à discussão social que permeou as modificações de visão de mundo do europeu do século XVIII foi o lluminismo. Segundo os lluministas tudo o que foge à razão deve ser combatido, no sentido que a racionalidade leva à reflexão, e esta à liberdade de opinião. Em princípio, o movimento preocupou-se em denunciar os abusos do estado absolutista, cujos privilégios passaram a ser condenados. A mudança de "visão de mundo" e as questões filosóficas em torno da felicidade e das condições de vida do homem refletiram-se na produção científica e fortemente na produção artística. Também se deve considerar que a pobreza da população comum era extrema, a expectativa de vida era de menos de vinte anos, não havia tempo para o lazer. A produção artística que anteriormente era encomendada pela Igreja ou pelos nobres, passou a ter menos procura (especialmente na Inglaterra) e os artistas também tiveram que se adaptar buscando novos clientes (os novos ricos da burguesia) que ao serem retratados buscavam reconhecer-se nas obras (diferentemente dos nobres da Idade Média) (GOMBRICH, 1981, p. 325).

Alguns reflexos de como se vê a ciência e a arte hoje (e a função social de cada uma), ainda são reminiscências daquele período e este pode ser o tema gerador de um processo dialógico com os alunos durante a atividade com a tela de Joseph Wright. 


\section{Trajetória de investigação}

A estratégia de pesquisa foi do tipo observação participante, na qual o investigador procurando conhecer e deixando-se conhecer, estuda e elabora um registro escrito e sistemático de tudo aquilo que ouve e observa (BOGDAN, 1994, p. 16). Os procedimentos de análise de dados coletados em sala de aula caracterizam a investigação qualitativa em educação. Houve esforço por parte do investigador na eliminação de preconceitos intelectuais e os planos (flexíveis) evoluíram de acordo com o desenvolvimento do processo, não havendo exigência de comprovação de uma hipótese anterior. A pesquisa foi realizada em múltiplos locais e seguiu os passos do que se conhece por método comparativo constante (BOGDAN, 1994, p. 101). Os dados principais obtidos no estilo cooperativo compreendem os registros das observações feitas em sala, os comentários do observador, as atividades realizadas pelos alunos e todos os elementos necessários para pensar de forma organizada e profunda acerca da investigação feita.

\subsection{Sobre as atividades elaboradas como instrumento de pesquisa}

As atividades planejadas e desenvolvidas em sala têm como tema gerador a Arte Urbana. Seguem os três momentos pedagógicos: a) ER - estudo da realidade (descodificação inicial, etapa na qual prevalece a fala do educando, cabe ao professor ouvir, entender, questionar); b) OC organização do conhecimento (predomina a fala do educador que orienta e propicia atividades que permitam o salto de conhecimentos dos quais o educando não era portador) e c) AC aplicação do conhecimento (etapa de recodificação na qual não predomina a fala de um sujeito da educação sobre o outro, mas ambos ampliam os horizontes dos seus conhecimentos anteriores) (PERNAMBUCO apud DELIZOICOV, 2011, p. 167). Descrição sucinta das atividades:

Atividade 1 - Etapa ER - Leitura de dois textos, o primeiro compilado a partir de jornal de grande circulação sobre a vida do artista urbano Skor, do qual há grafites nos bairros da cidade onde foi desenvolvido o trabalho. O segundo é CIENTISTAS DESCOBREM QUAL A FUNÇÃO DAS LISTRAS DAS ZEBRAS, e foi escolhido com a intenção de dar subsídios para a discussão pretendida sobre as relações da Ciência com o cotidiano. Após a leitura os alunos continuam a discussão que permeou as leituras e respondem as 04 questões propostas. 0 objetivo é provocar a percepção que o aluno tem do que é uma aula de Física (desequilibração para gerar a etapa posterior) e oportunizar a leitura e a reflexão sobre como a ciência e a arte são áreas do conhecimento construídas de forma diferente e também se expressam por linguagens diversificadas. Termos trabalhados: teoria, postulado, conceito.

Atividade 2 - Etapa ER -Apresentação de slides “Está a Física envolvida na Arte?" organizados a partir do tema gerador Arte Urbana. Momento de ouvir a fala do outro, questionar, "provocando os alunos" tanto no que pode ser visualizado (sombras, cores e texturas) quanto no conteúdo dos temas que podem ser gerados pelo inicial. Ao final os alunos receberam uma 
imagem "sem as sombras" e são solicitados a reconhecer a fonte de luz e esboçar as sombras dos elementos.

Atividade 3 - Etapa OC - Aula expositiva dialogada para sistematização dos conceitos tratados nas duas anteriores, com proposição de atividades que possibilitem o acesso às informações de forma organizada e permanente. É utilizado o livro texto (PNLD).

Atividade 4 - Etapa OC - Palavras cruzadas "Óptica e Arte" planejada para que o aluno exercite o uso do vocabulário utilizado nas aulas de óptica de forma mais lúdica que nos exercícios tradicionais. Há "mistura" de termos da Física, da Arte e do Ensino. O objetivo é a sistematização dos conhecimentos de termos e conceitos já utilizados e a redução da reserva que os educandos geralmente apresentam para incorporar seu uso.

Atividade 5 - Etapa OC - Discurso sistematizado, porém permeado de contribuições do grupo, sobre aplicações da propagação retilínea da luz. Exercícios que relacionam os tamanhos do objeto e da sombra. Ao final da aula os alunos são convidados a construir uma câmera escura (cuja apresentação foi feita contextualizada na história).

Atividade 6 - Etapa AC - Atividade com a tela "An Experiment on a Bird in the air pump" (1768) de Joseph Wright. A imagem escolhida traz uma cena da ciência entre a magia e o conhecimento. A expectativa é de que a cena traga de volta a discussão (iniciada nas atividades 1 e 2) sobre o papel da ciência na formação cultural da sociedade e do artista como um profissional observador e capaz de retratar, para a posteridade, fatos ocorridos em determinado momento histórico. A atividade escrita que os alunos responderam continha questionamentos referentes à identificação dos efeitos luminosos presentes na imagem e sua compreensão.

1 Esta tela pode ser melhor visualizada no seguinte link http://www.abcgallery.com/w/wright21.html, ou no livro de Cumming (1998) p.68 e 69, onde estão apresentadas outras reflexões sobre a tela.

DOI: Em andamento. 


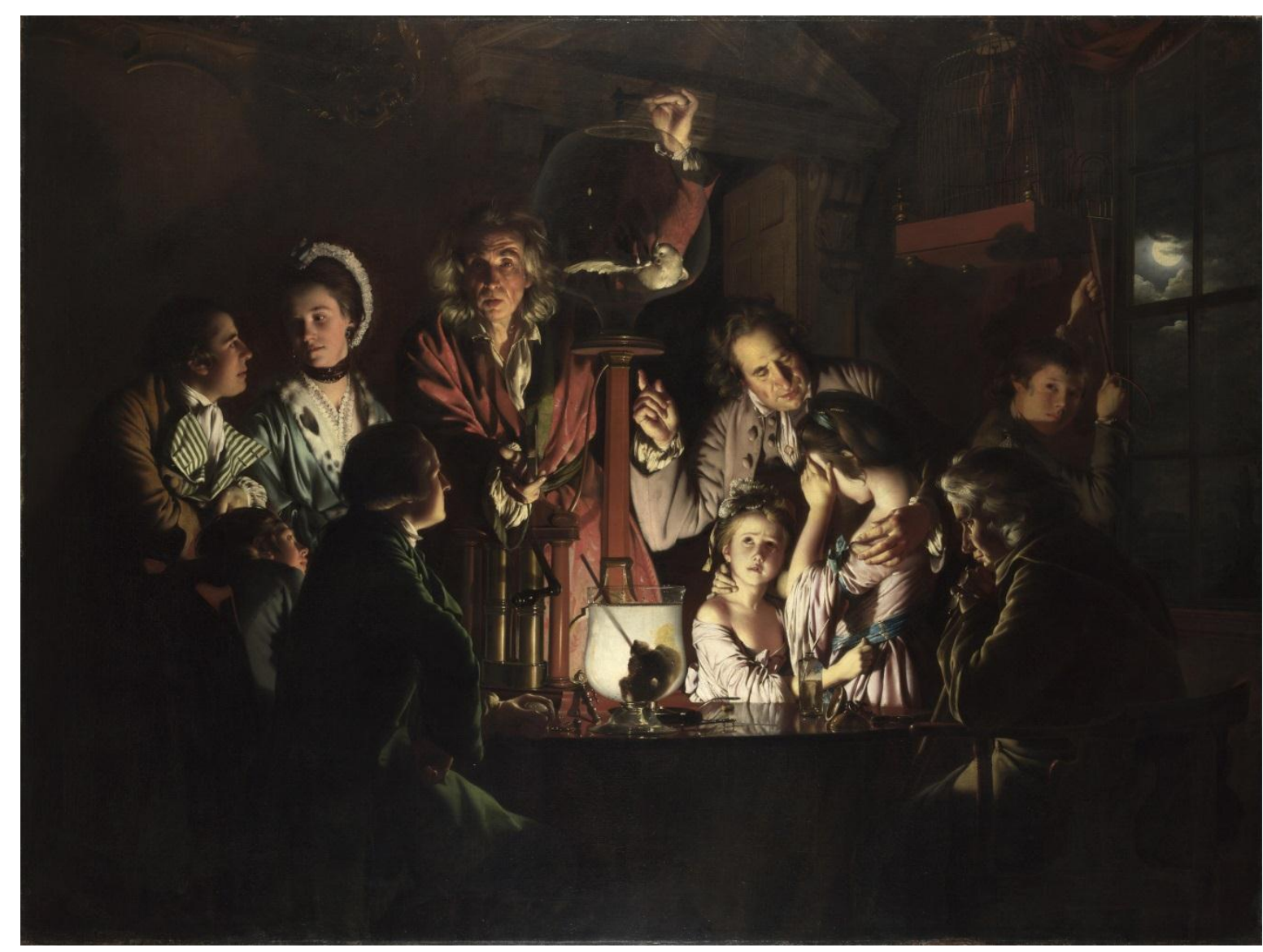

Figura 1 - Tela "An experiment on a Bird in the air pump", 1768.

(Fonte: Olga's Gallery)

\subsection{Dos procedimentos de análise e resultados obtidos}

Os procedimentos de análise incluíram: a descrição dos sujeitos da pesquisa, a descrição dos eventos com comentários do observador (retirados do diário de investigação), a utilização da transcrição de algumas falas dos educandos e a avaliação dos registros nas atividades escritas. A categoria geral de análise definida foi a que contempla a Perspectiva dos Sujeitos, o que é consoante com a concepção de educação freiriana norteadora da pesquisa centrada nos sujeitos envolvidos e nas suas vivências. As unidades de codificação de respostas foram buscadas e definidas durante a análise que incluiu todas as fontes de dados investigados, seguindo a prática do MEA (Modelo de Estratégia Argumentativa).

$\mathrm{Na}$ etapa de Investigação (levantamento de temas geradores presentes no universo do aluno e na comunidade onde ele vive) e sobre práticas pedagógicas que se utilizam do tema gerador (cuja base teórica é freiriana), e particularizando para o ensino de ciências, em dinâmicas de sala de aula (DELIZOICOV et al, 2011):

"Os temas geradores foram idealizados como um objeto de estudo que compreende o fazer e o pensar, o agir e o refletir, a teoria e a prática, pressupondo um estudo da realidade em que emerge uma rede de relações 
entre situações significativas individual, social e histórica, assim como uma rede de relações que orienta a discussão, interpretação e representação dessa realidade."

Os resultados obtidos corroboram a ideia de que a Arte Urbana faz parte do universo dos estudantes e que se apresenta como um instrumento capaz de aproximar as falas do educador e do aluno, incentivar a participação dos educandos e principalmente desmistificar a presença de preconceitos (contra a arte urbana pelo professor) e (contra a aula de Física pelo grupo). A figura 02 apresenta graficamente o resultado quantitativo da pesquisa feita. Considerando 85 sujeitos pesquisados, 10 não compareceram e 03 não participaram. Do universo de 72 pesquisados houve 33 respostas citando Arte Urbana e 39 dividindo todas as demais respostas. Reitera-se que esta etapa, de Investigação Temática, da qual aqui se apresenta os resultados também se mostrou instrumento que possibilita o aluno perceber que a Física está presente no mundo que o cerca (e nas coisas que ele gosta), diminuindo a rejeição pela disciplina.

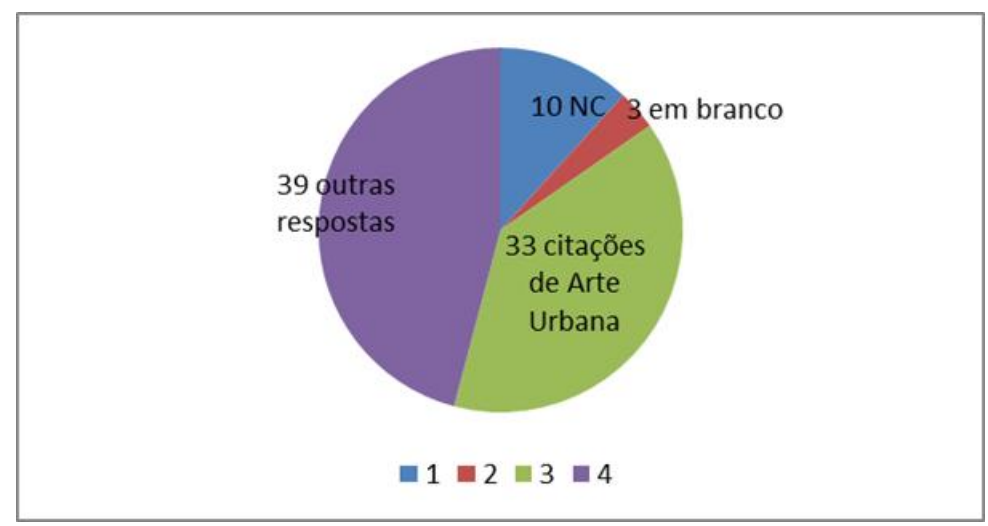

Figura 2 - Resultado da pesquisa sobre Arte Urbana como tema presente no Universo dos estudantes. Total de 85 participantes.

Foi possível afirmar que se estabeleceu um processo dialógico nas aulas expositivas, pois o conteúdo apresentado de forma organizada já tinha significado prévio e as discussões que se seguiram demonstraram que o interesse e o uso dos termos adequados foi ampliado.

Quanto à problematização com a tela de Joseph Wright, a técnica do artista incentivou os alunos a questionarem a representação de sombras e a contribuição de cada fonte luminosa para a formação dos fenômenos luminosos presentes. Houve grande interesse na imagem da Lua, e o resgate da discussão acerca do papel do cientista e do artista da época surgiu naturalmente para turma.

Como obstáculos enfrentados para o desenvolvimento desta pesquisa foram identificados: o reduzido número total de aulas de Física por bimestre letivo (em torno de 22 aulas) e a correspondente dificuldade em se planejar os conteúdos previstos pela ementa e a 
pouca relevância dada para os temas relativos à Óptica, que pode ser observada na forma como geralmente são tratados pelos professores (são previstas poucas aulas para a temática e sempre no final do quarto bimestre). Os autores justificam esta realidade argumentando que a Óptica Geométrica não é vista pelos docentes como "a porta de entrada" de conteúdos como a Introdução à Física Moderna e outros relativos às aplicações tecnológicas contemporâneas, cuja ministração é fortemente sugerida pelos documentos oficiais, como os PCN e as Diretrizes Curriculares, mas que em geral, não vão a efeito.

\section{Considerações finais}

Este texto teve como objetivo apresentar a etapa de Investigação Temática que faz parte de uma pesquisa qualitativa em educação, cuja concepção norteadora foi a pedagogia dialógicoproblematizadora de Paulo Freire. As atividades didático pedagógicas foram planejadas de forma flexível permitindo que os sujeitos envolvidos na pesquisa fossem ouvidos e privilegiadas suas falas.

São promissoras as possibilidades de incrementar o ensino de Física numa abordagem que busque reflexão sobre o papel da Ciência na construção coletiva e histórica do conhecimento, enriquecida pelas suas relações com a Arte. Há um universo há ser explorado, tanto na dimensão pedagógica destas relações, quanto na dimensão acadêmica de pesquisa. Outros temas científicos presentes nas ementas escolares podem se relacionar com manifestações artísticas, inclusive com aquelas que fugiram do escopo da presente investigação, como a poesia e a música. São possíveis diferentes aprofundamentos dos referenciais norteadores que podem ficar como proposta para futuras inserções de âmbito interdisciplinar, por exemplo, trazendo as contribuições da Filosofia ou do próprio fazer artístico e científico.

Os resultados demonstram que a metodologia utilizada contribui de maneira fundamental para os resultados em sala de aula, sendo capaz de alterar positivamente a relação professor/aluno e a relação dos estudantes com a disciplina escolar Física.

\section{Agradecimentos}

Os autores agradecem ao Colégio Estadual Leôncio Correia, em especial ao Professor Airton Stori pelas importantes contribuições, ao Colégio Estadual Santa Cândida e a Escola Estadual Ernani Vidal pela participação na pesquisa.

\section{Referências}


ALMEIDA, D. Da Suíça a Maringá, grafiteiro Skor dá vida aos espaços cinzas e feios. Gazeta do Povo, 06.mar.2011. Disponível em http://www.gazetadopovo.com.br/caderno-g/da-suica-amaringa-grafiteiro-skor-da-vida-aos-espacos-cinzas-e-feios-djpge3bcw58cb9ah0io7gvgwe Acesso em 29.mar.2015

BOGDAN, R.; BIKLEN, S. Investigação Qualitativa em Educação. Porto: Porto Editora LDA, 1991.

BRASIL. Ministério da Educação. Parâmetros Curriculares Nacionais Ensino Médio. 1999. Disponível em: http://portal.mec.gov.br/seb/arquivos/pdf/ciencia.pdf

CUMMING, R. Para entender a Arte. São Paulo: Ática, 1998.

DELIZOICOV, D.; ANGOTTI, J. A.; PERNAMBUCO, M.M. Ensino de Ciências: fundamentos e métodos. 4ed. São Paulo: Cortez Editora, 2011.

ESTEVAN, A. Cientistas descobrem qual a função das listras das zebras. Mundo Animal. National Geographic Brasil. São Paulo: Editora Abril, Fev.2012. Disponível em:

http://viajeaqui.abril.com.br/materias/noticias-zebras-listras Acesso em 29.mar.2015.

FREIRE, Paulo. Pedagogia do Oprimido. Rio de Janeiro: Paz e Terra, 1987.

FREIRE, P. A Pedagogia da Autonomia - Saberes necessários à prática educativa. 43ed. São Paulo: Paz e Terra, 1996.

GOMBRICH, E. H. A História da Arte. 2ed. Rio de Janeiro: Zahar Editores, 1981.

GORRI, A. P.; SANTIN FILHO, O. Representação de Temas Científicos em Pintura do Século XVIII: Um Estudo Interdisciplinar entre Química, História e Arte. Química Nova na Escola, São Paulo, Vol.31, N³, p.184-189, Ago. 2009.

PIETROCOLA, M. Curiosidade e Imaginação - Os caminhos do conhecimento nas Ciências, nas Artes e no Ensino. In: Ensino de Ciências: Unindo a Pesquisa e a Prática. São Paulo: Pioneira Thomson Learning, 2004. p.119-133.

Milene Dutra da Silva - Universidade Tecnológica Federal do Paraná, Programa de Pós-Graduação em Formação Científica, Educacional e Tecnológica

Mário Sérgio Teixeira de Freitas - Universidade Tecnológica Federal do Paraná, Departamento de Física, Programa de Pós-Graduação em Formação Científica, Educacional e Tecnológica

Awdry Feisser Miquelin - Universidade Tecnológica Federal do Paraná, Departamento de Física, Programa de Pós-Graduação em Formação Científica, Educacional e Tecnológica 